\title{
EXTENDED TECHNOLOGY ACCEPTANCE OF MOBILE TECHNOLOGY IN HIGHER ED: A RELIABILITY \& VALIDITY TEST OF A SCALE
}

\author{
Dennis Pires, Bethune Cookman University,dennis.pires@cookman.edu \\ Leila Halawi, Embry Riddle Aeronautical University, halawil@erau.edu
}

\begin{abstract}
The objective of this research study is to study the mobile technology acceptance of educators in the higher education industry in the United States. This study utilized the Chen et al. (2013) extended technology acceptance model, that extended the original Davis (1989) TAM. The study incorporated path analysis to determine estimates of the magnitude and significance of hypothesized causal connections between sets of the study variables. The researchers investigated the reliability of the survey instrument for the sample with Cronbach's alpha. There were five variables of interest in the study, perceived resources, perceived ease of use, perceived usefulness, attitude toward use, behavioral intention, and technology use with two dimensions, incorporating frequency of use and duration of use. The research question, hypotheses, and current state of research are presented and discussed.
\end{abstract}

Keywords: mobile technology, extended technology acceptance model, higher education, Amos, path analysis.

\section{INTRODUCTION}

With technology becoming ubiquitous, it is essential that technologies adopted in the corporations serve the business functions and improve overall business performance. According to Siau and Shen (2003), mobile technology has gained importance and popularity in organizations, and numerous companies have openly accepted and incorporated new and improved technologies (Sheng, Nah, \& Siau, 2005) to improve business functions and business performance. Mobile technologies with the capabilities of having several functions into a single device (Thornton and Houser, 2004) have become an integral part of the corporate culture. The most touted advantage of mobile technology is mobility (Sarker and Wells, 2003) and with companies growing larger and further as a result of shrinking geographic boundaries, it is an asset to have technologies that can serve on the go.

Mobile technologies have made business activities possible anytime, and anywhere (Varshney and Vetter, 2000). Businesses have incorporated technologies in various business functions and with newer mobile technologies being introduced in the market at a rapid pace; the businesses need to access the impact of the newer technologies on the overall performance of the business.

It is important for higher education institutions to understand educator constraints in adopting mobile technology, and their acceptance of mobile technology for instructional use. The purpose of the study was to contribute to the body of knowledge in the field of information technology management by investigating mobile technology acceptance in higher education from educators' perspectives. As new electronic devices continue to appear in the marketplace, the use of technologies may have both intended and unintended implications for society and education (Capo, 2011). Egbert, Paulus, \& Nakamichi, (2002) stated that, when teachers received adequate training and resources, their use of technology as well as their confidence and attitudes toward the technology improved.

The purpose of the proposed study was to contribute to the body of knowledge in the field of information technology management by conducting a study to investigate the technology acceptance of mobile technology in higher education from an educator perspective. The current study used a path analysis design to measure the mediating effects on the use of mobile technology in higher education.

The paper begins by reviewing the relevant literature in the area of technology acceptance within the mobile technologies. We then present the comprehensive model used. The final section explains our preliminary findings and the current state of research. 


\section{MOBILE TECHNOLOGIES}

Mobile technologies are those that enable mobility, computing, and the ability to reach beyond the physical limitations (Kim, Mims, and Holmes, 2006). The emphasis on accepting and incorporating new technologies has increased with businesses expanding their reach continuously to reach global markets. It is technology that enables this growth of businesses to unlimited opportunities and it is the technological advances that enable business corporations to engage in business activities effectively and efficiently despite the obstacles of time and distance. Lee and Grewal (2004) state that modern corporations must adopt and assimilate new technologies to build and sustain competitive advantage.

The existing literature on mobile technologies has focused on different aspects such as mobile technologies such as how to best incorporate mobile technologies (Liang, Huang, Yeh, and Lin, 2007), gaining business volume from mobile technologies (Kornak, Teutloff, and Welin-Berger, 2004), and mobiles communications and mobile services in business (Siau and Shen, 2003).

Given the various technological advances and the acceptance and incorporation of various technologies in the business world, the modern corporations (Lee and Grewal, 2004) need to access the fast-growing technologies and their impact on business performance.

For the purposes of this research, mobile technology includes any portable computing device with touch-screen features, capable of running applications and connecting to the Internet via wireless and wireless data networks. The study examined educator utilization of smart phones and tablet computers with WI-FI and wireless data capabilities in the higher education industry.

\section{TECHNOLOGY ACCEPTANCE MODEL}

The original Technology Acceptance Model (TAM) examines the effect of users' attitudes and beliefs on user acceptance of information technology or rejection of such technologies (Jairak et al., 2009). Fishbien and Ajien's (1990) Theory of Reasoned Action across academic disciplines supplied the basis for The Technology Acceptance Model proposed by Davis (1989).

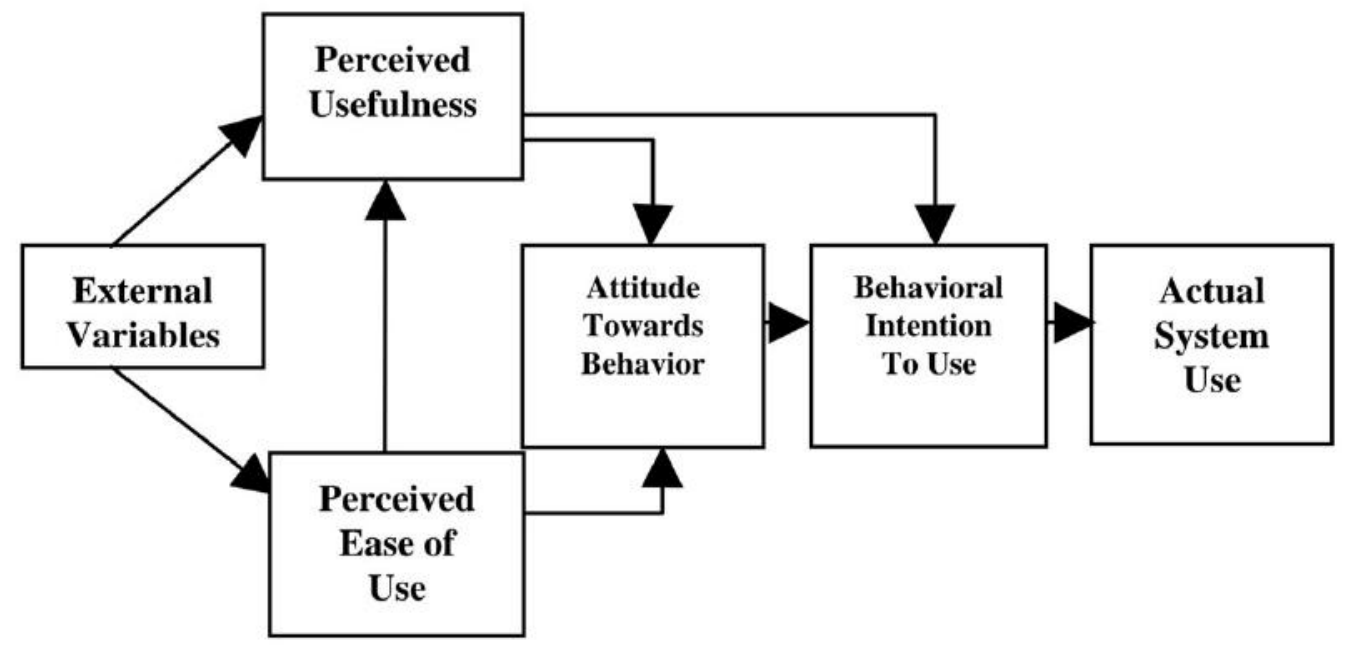

Figure 1. Original Technology Acceptance Model

Source: Jairak, Praneetpolgrang, and Mekhabunchakij (2009) 


\section{Unified Theory of Acceptance and Use of Technology}

The Unified Theory of Acceptance and Use of Technology evolved from the Technology Acceptance Model in an effort to enhance the use of extensions and variations developed from future research studies (Lin, Zimmer, \& Lee, 2013).

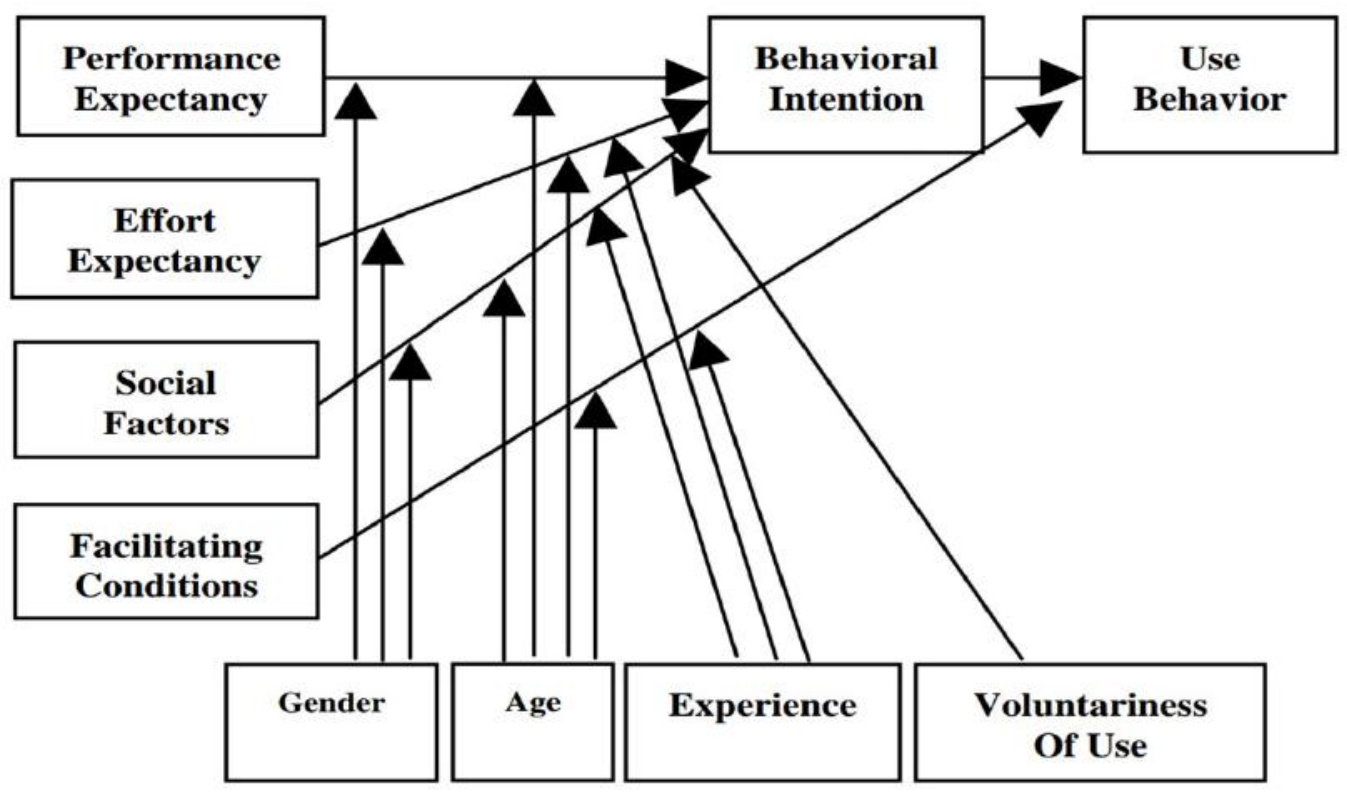

Figure 3. The Unified Theory of Acceptance and Use of Technology Source: Jairak, Praneetpolgrang, and Mekhabunchakij (2009)

TAM suggests a causal relationship between perceived usefulness, perceived ease of use, attitude towards use, behavioral intent to use mobile technology, and the actual use of mobile technology. The extended technology acceptance model used in this study derived from the Chen et al. (2013) study that adopted the extended technology acceptance model from Mathieson et al. (2001) and $\mathrm{Ku}(2009)$.

\section{RESEARCH METHODOLOGY}

Path analysis goes beyond regression to allow for the analysis of more complicated models (Streiner, 2005). Path analysis is a variant of multivariate regression analysis in which a path or flow diagram and path coefficients represents causal relations between several variables and provide estimates of the strength of relationship between two variables when holding all other variables constant (Jupp, 2006).

This study utilized a previously designed extended technology acceptance model by Chen et al. (2013). Chen et al.'s model accounted for all the variables necessary to study the acceptance of mobile technology based on prior research. Statistical analysis using regression analysis will measure the statistical strength of each pathway in the path analysis model. Using a path analysis multivariate research design, the research will examine the acceptance of mobile technology for educators and learners in higher education. Because technology acceptance could have multiple causes, the topic was better suited to a multivariate research design such as path analysis.

The sample size consisted of 180 participants with a confidence level of $.95 \%$, response distribution of $50 \%$, and a margin error of 5\%. The sample included part-time and full-time educators in higher education currently teaching at an undergraduate or graduate level in the United States that agreed to complete the voluntary survey on SurveyMonkey ${ }^{\circledR}$. The participants were either full-time, part-time, or adjunct faculty teaching at an undergraduate or graduate program that met the following criteria: 
- Any age, either male or female, and any race

- Current educator in higher education at the undergraduate or graduate level

- Currently teaching part-time or full-time

- $\quad$ Live in the United States

The participation in the study was voluntary and the participants could opt out of the study anytime during the survey. Originally, data collection was set for a four-week period; however, given the overwhelming response from participants, data collection stopped after seven days because the number of survey responses exceeded the required 138 participants. The researchers exported the data from SurveyMonkey®, placed it in an Excel spreadsheet, and uploaded it into Statistical Package for Social Sciences (SPSS) (v23.0) for data analysis.

\section{Data Analysis}

AMOS 23.0, computer software marketed by SPSS is used for data analysis (Arbuckle, 2008). Path analysis usually involves the analysis and comparison of two models, a full model with all the components included and a reduced model, which has some of the paths deleted if they do not contribute significantly to the outcome. Path analysis includes, as special cases, many well-known conventional techniques, such as regression analysis. The path coefficients for the proposed analyses will be derived from a series of linear regression analyses. The overall fit measures that will used to determine whether the data fit the proposed model will include several indices generated by the software.

\section{Validity and Reliability}

The study incorporated path analysis to determine estimates of the magnitude and significance of hypothesized causal connections between sets of the study variables. According to Wuensch (2012), path analysis, developed by Wright (1934), could determine whether a multivariate set of non-experimental data fits well with a particular causal model. The researcher checked data accuracy manually while entering the data and rechecked to ensure the data entered was free of errors.

\section{Sample Demographics}

Data derived from 181 educators who worked full or part-time at a college or university in the United States. Sixtythree percent $(N=114)$ were female and $37 \%(N=67)$ were male. The three largest age groups were $45-54(34.3 \%$, $N=62), 35-44(27.6 \%, N=50)$, and $55-64(21 \%, N=38)$, which represented $82.9 \%(N=150)$ of the sample. See Table 1.

Table 1. Age of Educators

\begin{tabular}{lccc}
\hline Age & $N$ & $\%$ & Cumulative \% \\
\hline 25 to 34 & 15 & 8.3 & 8.3 \\
35 to 44 & 50 & 27.6 & 35.9 \\
45 to 54 & 62 & 34.3 & 70.2 \\
55 to 64 & 38 & 21.0 & 91.2 \\
65 to 74 & 15 & 8.3 & 99.4 \\
75 or older & 1 & 0.6 & 100.0 \\
Total & 181 & 100.0 & \\
\hline
\end{tabular}


Approximately one-third $(33.1 \%, N=60)$ of participants had taught at a college or university for $6-10$ years; $26.5 \%$ $(N=48)$ had taught for 16 or more years; and $21.5 \%(N=39)$ had taught at a college or university $0-5$ years. Educator tenure is in Table 2.

Table 2. Years as an Educator at a College and/or University

\begin{tabular}{lccc}
\hline Years & $N$ & $\%$ & Cumulative\% \\
\hline 0-5 Years & 39 & 21.5 & 21.5 \\
6-10 Years & 60 & 33.1 & 54.7 \\
11-15 Years & 34 & 18.8 & 73.5 \\
16 Years or More & 48 & 26.5 & 100.0 \\
Total & 181 & 100.0 & \\
\hline
\end{tabular}

\section{Instrument Reliability}

The researchers investigated the reliability of the survey instrument for the sample with Cronbach's alpha. There were five variables of interest in the study, perceived resources, perceived ease of use, perceived usefulness, attitude toward use, behavioral intention, and technology use with two dimensions, incorporating frequency of use and duration of use. Cronbach's alpha associated with the mean correlation between each pair of items and the number of items in the scale. Therefore, a scale must have a minimum of two items in order to compute for reliability. Thus, the researchers could not compute the reliability of the subscales for technology use because each dimension had only one item on the survey. The internal consistency for the subscales ranged from .745 for perceived resources to .903 for perceived ease of use. Reliability coefficients are in Table 3 .

Table 3. Reliability Coefficients

\begin{tabular}{lcc}
\hline Variable & $N$ of Items & Cronbach's alpha \\
\hline Perceived Resources & 3 & .745 \\
Perceived Ease of Use & 3 & .903 \\
Perceived Usefulness & 6 & .806 \\
Attitude Toward Use & 5 & .827 \\
Behavioral Intention & 3 & .902
\end{tabular}

\section{Hypothesis Testing}

Eleven hypotheses associated with the primary research question, as follows:

Hypothesis 1. Perceived resources will have a positive direct effect on perceived usefulness.

Hypothesis 2. Perceived resources will have a positive direct effect on perceived ease of use.

Hypothesis 3. Perceived resources will have a positive direct effect on attitude toward using Mobile Technology.

Hypothesis 4. Perceived resources will have a positive direct effect on behavioral intention to use Mobile

Technology.

Hypothesis 5. Perceived ease of use will have a positive direct effect on perceived usefulness.

Hypothesis 6. Perceived ease of use will have a positive effect on attitude toward using mobile technology.

Hypothesis 7. Perceived usefulness will have a positive direct effect on attitude toward using mobile technology. 


\section{Issues in Information Systems}

Volume 20, Issue 4, pp. 167-174, 2019

Hypothesis 8. Perceived usefulness will have a positive direct effect on behavioral intention to use mobile technology.

Hypothesis 9. Attitude will have a positive direct effect on behavioral intention to use mobile technology. Hypothesis 10. Behavioral intention will have a positive direct effect on mobile technology use frequency. Hypothesis 11. Behavioral intention will have a positive direct effect on mobile technology use length of time.

Figurel illustrates the path diagram.

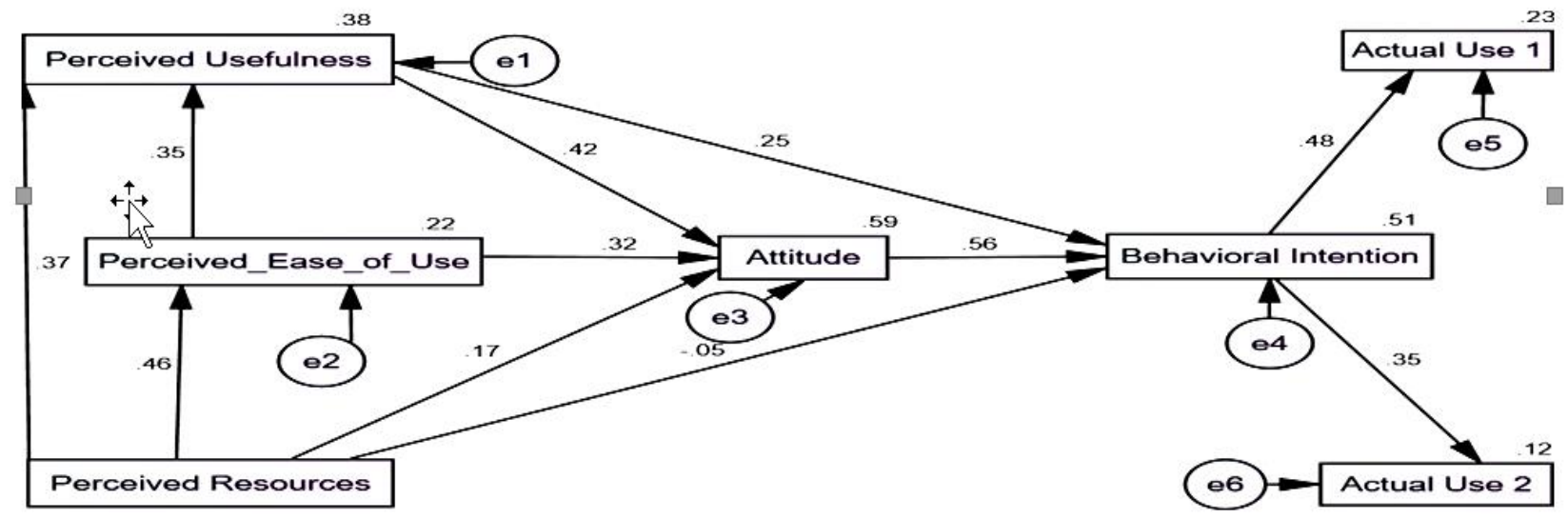

Figure 1. The path diagram

\section{CONCLUSION}

The survey instrument, adopted from the Chen et al. (2013) study, extended the original TAM model and used the TAM theoretical model for its study. The survey instrument consisted of 26 questions based on a five-point Likert scale, ranging from Strongly Agree to Strongly Disagree. The first four questions collected demographic information. The remaining 22 questions measured technology acceptance and identified the factors that influenced the acceptance of mobile technology by current educators in higher education within the U.S.

Reliability and validity tests were conducted and we proposed 11 hypotheses. This is a research in progress.

Path analysis with AMOS 23 will be used to test the hypotheses and the subsequent path to the model.

The study provides an important theoretical framework for decision-making for educational institutions as they seek improvement in user acceptance of technology in the higher education setting. The study adds to the knowledge in the field of information technology by providing statistical research that uses path analysis to disentangle the various causal processes underlying the acceptance of technology in higher education.

\section{REFERENCES}

Arbuckle, J. L. (2008). Amos 17.0 User's Guide. Chicago: SPSS

Capo, B. (2011). Web 2.0 technologies for classroom instruction high school teachers' perception and adoption factors. The Quarterly Review of Distance Education, 12(4), 235-253.

Chen, B., Sivo, S., Seilhamer, R., Sugar, A., \& Mao, J. (2013). User acceptance of mobile technology: a campuswide implementation of blackboard mobile ${ }^{\mathrm{tm}}$ learn application. Journal of Educational Computing Research, 49(3), 327-343

Davis, F. D. (1989). Perceived usefulness, perceived ease of use, and user acceptance of information technology. MIS Quarterly, 13(3), 319-340. 
Duncan-Howell, J. and Lee, K. T. (2007). M-learning: finding a place for mobile technologies within tertiary education settings. Proceedings of the ascilite conference, Singapore 2007.

Egbert, J., Paulus, T., \& Nakamichi, Y. (2002). The impact of CALL instruction on language classroom technology use: a foundation for rethinking CALL teacher education? Language Learning \& Technology, 6(3), 108126.

Jairak, K., Praneetpolgrang, P., \& Mekhabunchakij, K. (2009). An acceptance of mobile learning for higher education students in Thailand. Special Issue of the International Journal of the Computer, the Internet and Management, 17(SP3), 36.

Jupp, V. (2006). The sage dictionary of social research methods. London, England: Sage Publication

Kim, S. H., Mims, C., \& Holmes, K. P. (2006). An introduction to current trends and benefits of mobile wireless technology use in higher education. Association for the Advancement of Computing in Education Journal, 14(1), 77-100.

Ku, C. H. (2009). Extending the technology acceptance model using perceived user resources in higher education web-based online learning courses. Doctoral dissertation, University of Central Florida, Orlando, FL

Kornak, A., Teutloff, J., and Welin-Berger, M. (2004). Enterprise guide to gaining business value from mobile technologies. Hoboken, NJ: Wiley Publishing, Inc.

Lee, R. P., and Grewal, R. (2004). Strategic responses to new technologies and their impact on firm performance. Journal of Marketing, 68(4), 157-171.

Liang, H., Saraf, N., Hu, Q., \& Xue, Y. (2007). Assimilation of enterprise systems: The effect of institutional pressures and the mediating role of top management. MIS Quarterly, 31, 59-87.

Liang, T., Huang, C., Yeh, Y., and Lin, B. (2007). Adoption of mobile technology in business: a fit-viability model. Industrial Management \& Data Systems, 107(8), 1154-1169.

Lin, S., Zimmer, J. C., \& Lee, V. (2013). Podcasting acceptance on campus: The differing perspectives of teachers and students. Computers \& Education, 68, 426-428

Prensky, M. (2001). Digital natives, digital immigrants. On the Horizon, 9(5), 1-6.

Sarker, S., \& Wells, J. D. (2003). Understanding mobile handheld devices use and adoption. Communications of the $A C M, 46(12), 35-40$.

Sheng, H., Nah, F. F. H., \& Siau, K. (2005). Strategic implications of mobile technology: a case study using valuefocused thinking. The Journal of Strategic Information Systems, 14(3), 269-290.

Siau, K., and Shen, Z. (2003). Building customer trust in mobile commerce. Communications of the ACM, 46(4), 91$94 .$.

Siau, K., and Shen, Z. (2003). Mobile communications and mobile services. International Journal of Mobile Communications. 1(1-2), 3-14.

Streiner, D. L. (2005). Finding our way: an introduction to path analysis. The Canadian Journal of Psychiatry, $50(2), 115-122$. 


\section{Issues in Information Systems}

Volume 20, Issue 4, pp. 167-174, 2019

Thornton, P., and Houser, C. (2004). Using mobile phones in education. Proceedings of the 2nd International Workshop on Wireless and Mobile Technologies in Education. JungLi, Taiwan: IEEE Computer Society, 310.

Varshney, U., and Vetter, R. (2000). Emerging mobile and wireless networks. Communications of the $A C M, 43(6), 73-81$.

Wright, S. (1934). The method of path coefficient. The annals of mathematical statistics, 5(3), 161-215.

Wuensch, K. L. (2012). An introduction to path analysis. Retrieved from http://core.ecu.edu/psyc/wuenschk/MV/SEM/Path.pdf on February 6, 2015. 